\title{
Research on Flow Stability and Vibration of an Industrial Hydraulic Turbine
}

\author{
Xianghui Su ${ }^{1,2} \mathbb{1}$, Zixian Cao ${ }^{1}$, Yi Li ${ }^{1}$, Yuzhen Jin ${ }^{1}$ and Zhenji Tang ${ }^{1, *}$ \\ 1 Key Laboratory of Fluid Transmission Technology of Zhejiang Province, Zhejiang Sci-Tech University, \\ Hangzhou 310000, China; suxianghui@zstu.edu.cn (X.S.); caozixian@tom.com (Z.C.); liyi@zstu.edu.cn (Y.L.); \\ gracia1101@foxmail.com (Y.J.) \\ 2 Changsha Research Institute of Mining and Metallurgy Co. Ltd., Changsha 410000, China \\ * Correspondence: 201820503004@mails.zstu.edu.cn
}

Citation: Su, X.; Cao, Z.; Li, Y.; Jin, Y.; Tang, Z. Research on Flow Stability and Vibration of an Industrial Hydraulic Turbine. Processes 2021, 9, 311. https://doi.org/10.3390/ pr9020311

\section{Academic Editor:}

Krzysztof Rogowski

Received: 3 January 2021

Accepted: 1 February 2021

Published: 7 February 202

Publisher's Note: MDPI stays neutral with regard to jurisdictional claims in published maps and institutional affiliations.

Copyright: (C) 2021 by the authors Licensee MDPI, Basel, Switzerland. This article is an open access article distributed under the terms and conditions of the Creative Commons Attribution (CC BY) license (https:// creativecommons.org/licenses/by/ $4.0 /)$

\begin{abstract}
Industrial hydraulic turbines, a kind of small-scaled turbine in a more compact and flexible application, are frequently used in hydrogen cracking, synthesis ammonia, and circulating water field. Besides the energy recovery efficiency, the working stability at variable speed situations is a critical issue, since its rotation speed changes with the flow parameters of the upstream. In this paper, a conventional turbine was numerically investigated under three different rotation speeds and its best efficiency points (BEPs). The velocity profiles, blade load, pressure fluctuation, and vibration features were discussed to form a comprehensive evaluation of turbine stability. The numerical results were validated through turbine external characteristic and vibration tests. The results indicate that the pressure pulsation and vibrations increase when it deviates from the rated rotation speed, but the relatively low flowrate point behaves better than the large point in the aspect of turbine stability; the main reasons are the angle of incidence and rotor circumferential vortex. The conclusions can provide significant reference for turbine hydraulic optimization and engineering application.
\end{abstract}

Keywords: hydraulic turbine; numerical simulation; hydraulic stability; circumferential vortex; pressure fluctuation

\section{Introduction}

Industrial hydraulic turbines can be an effective solution for fluid transportation processes and small-scaled hydropower for fluid energy recovery due to the advantages of low cost, easy maintenance, and satisfying efficiency. In practical configuration, these turbines convert fluid energy into mechanical energy, and drive a load device or variable speed generator directly when turbines operation change frequently; that is the turbine system. In this case, their working point, or BEP (best efficiency point), may change, and the rotation speed and high efficiency span of turbine may be deviated to adapt the various feeding flow and match different load devices [1-5].

In a thermal power plant, it employs high-pressure steam generated by burning coal to drive steam turbines to generate electricity. Since the coal contains sulfur and nitrate, it will cause environmental pollution when they are directly discharged into the atmosphere. Therefore, it is necessary to perform desulfurization and denitrify the flue gas. After the absorption liquid is pressurized by a water pump at the bottom of the desulfurization tower, it is sprayed at the top of the tower to remove pollutants from the flue gas so as to complete the desulfurization and denitrification. After that, the liquid for spraying is still at a high height and can be collected to drive the hydraulic turbine for fluid energy recovery instead of being discharged. Figure 1 shows the turbine working diagram in these applications and Figure 2 displays its installation and mechanical configuration. In the engineering practice, the power consumption and heating demand are diverse in different seasons; especially in high latitude regions of the northern hemisphere, the operation time in summer is long and the electricity demand is large, but the demand for electricity in 
winter is relatively reduced, even when there is a certain demand for heating. Therefore, the amount of smoke produced by coal burning varies greatly in different seasons, and so does the amount of water for desulfurization and denitrification, resulting in the turbine running at different speeds. This is the diverse working conditions and BEPs of turbine system.

Among these applications, there is an important question as to whether turbines can work in various BEPs with satisfied efficiency and working stability, which is still unclear now. The reported papers indicate that the working status and detail behaviors of a certain turbine system strongly rely on the feeding capacity, head, and the load device [6,7]. For this aim, it is necessary to investigate the internal flow differences, especially the hydraulic stability, of different BEPs at various rotation speeds.

At present, researchers have investigated the type selection, performance prediction, and optimization design by a lot of numerical simulations and experiments, and accumulated abundant design knowledge and usage experiences [1-4]. Additionally, factors about turbine operation security and stability are focused on, such as thrust force, pressure pulsation, and vibration. Compared with pump conditions, cavitation in turbine mode is even less pernicious [8,9]. As to axial thrust force, it is proven proportional to turbine capacity [10]. The behavior of turbine radial forces and vibrations is generally better than that of pump, the magnitude of turbine vibration equals with that of pump near the designed points and increases significantly as turbine feeding capacity [11]. For pressure pulsation, it has been proved that there is a significant pulsation phenomenon in the turbine, which is ultimately attributed to static and dynamic interference [12]. The pulsating characteristic of flow is due to the unsteady flow under the action of rotation [13].Still, there may appear other adverse factors, e.g., pressure fluctuation caused by rotor-static interaction [14], parts fatigue of flowing component [15], the noise, and vibration [16]. To sum up, the noted research covers the general aspects of performance and flow features of hydraulic turbine at rated point, but the internal flow structure and hydraulic stability at various speed, especially different BEPs, have not been reported [13,17-21]. For this aim, this paper attempts to quantify the flow characteristics of various rotation and reveal the further flow stability considering the comprehensive flow and induced pulsation to support the engineering application.

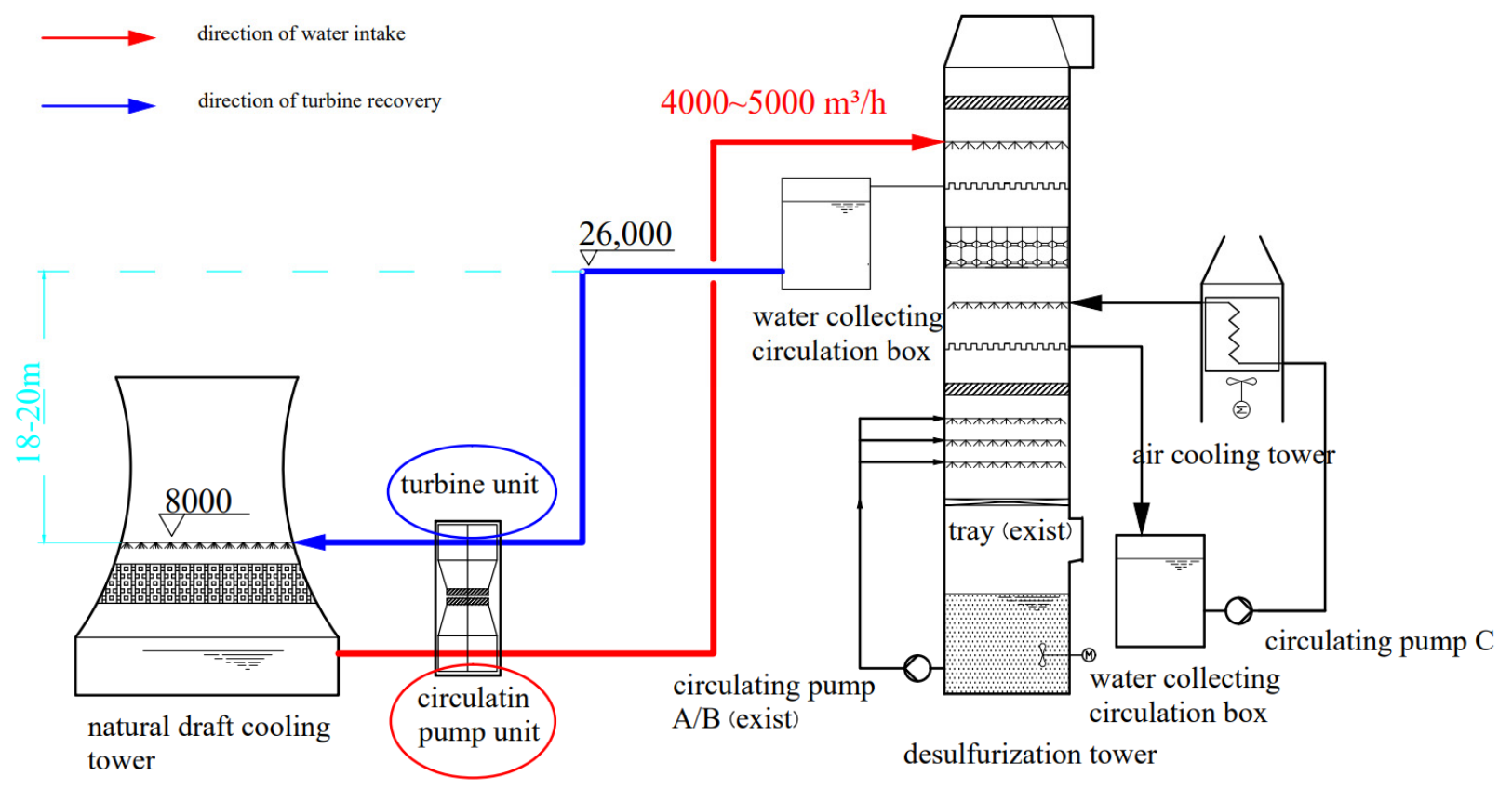

Figure 1. Turbine in desulfurization tower. 


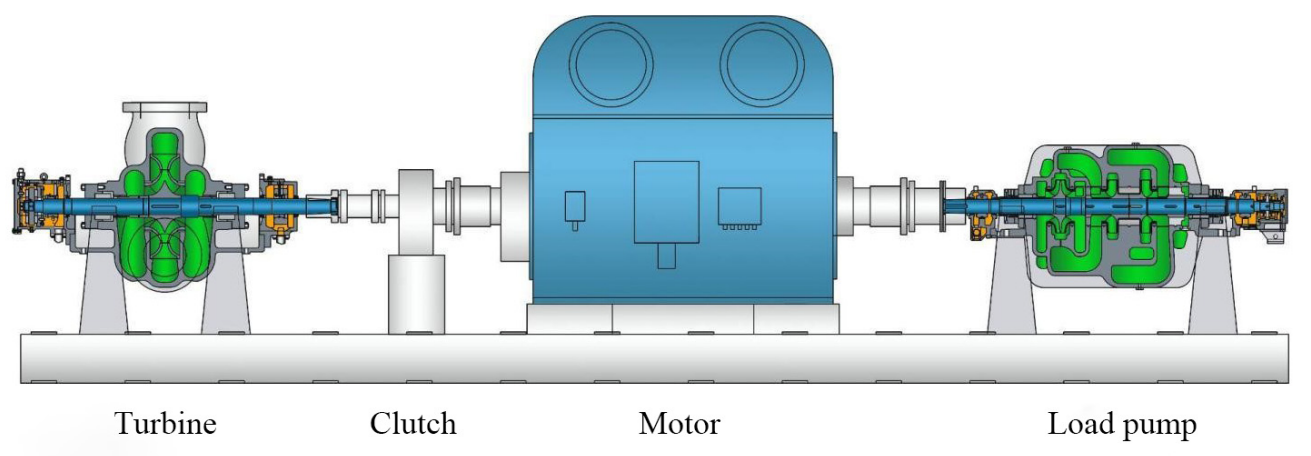

Figure 2. A real application of turbine.

\section{Research Object and Theoretical Analysis}

\subsection{Turbine Main Geometric Parameters}

A conventional turbine model was chosen to investigate the internal flow stability of various rotating speed. Its rated point was $Q=80 \mathrm{~m}^{3} / \mathrm{h}, H=20.3 \mathrm{~m}$, and $\mathrm{N}=1500 \mathrm{rpm}$. The main graph is shown in Figure 3 and geometric parameters are shown in Table 1.
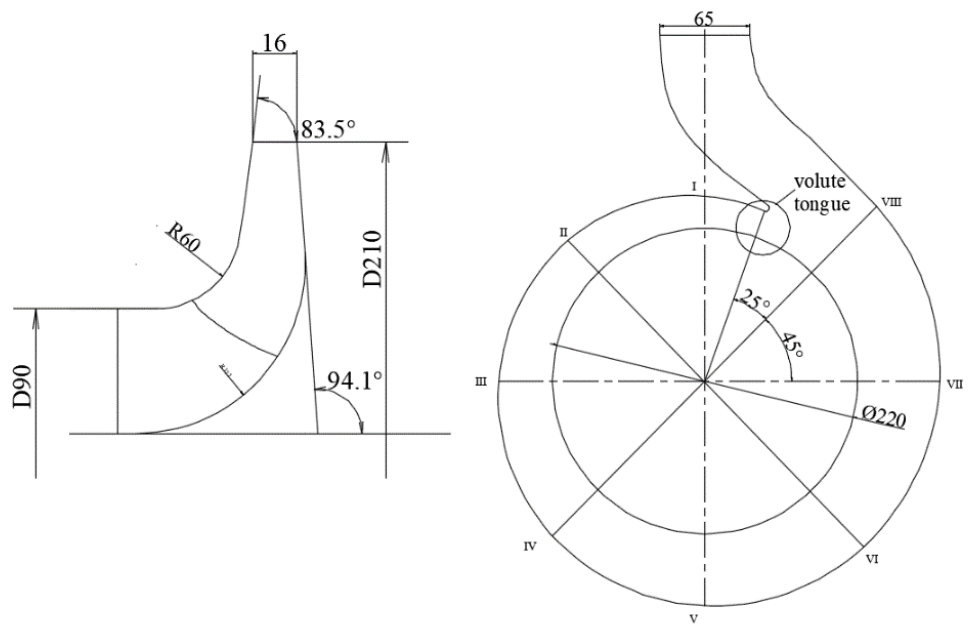

Figure 3. 2D hydraulic drawing of hydraulic turbine.

Table 1. Main geometric parameters of the turbine.

\begin{tabular}{cc}
\hline Parameter & Value \\
\hline$D_{1}(\mathrm{~mm})$ & 203 \\
$D_{2}(\mathrm{~mm})$ & 90 \\
$D_{3}(\mathrm{~mm})$ & 220 \\
$D_{4}(\mathrm{~mm})$ & 65 \\
$D_{h}(\mathrm{~mm})$ & 30 \\
$b_{2}(\mathrm{~mm})$ & 16 \\
$z$ & 6 \\
$\beta_{1}\left(^{\circ}\right)$ & 35 \\
$\beta_{2}\left(^{\circ}\right)$ & 15 \\
$\psi\left({ }^{\circ}\right)$ & 130 \\
\hline
\end{tabular}

As for this turbine, it has similar efficiency performance at different rotation speeds. The efficiencies of points A, B, and C by test are exhibited in Figure 4 as $79.5 \%, 79.8 \%$, and $80.3 \%$, corresponding to rotation speed of $1000 \mathrm{rpm}, 1500 \mathrm{rpm}$, and $2000 \mathrm{rpm}$, respectively. The following numerical investigations were performed to understand the flow stability and further performance differences on the three points. 


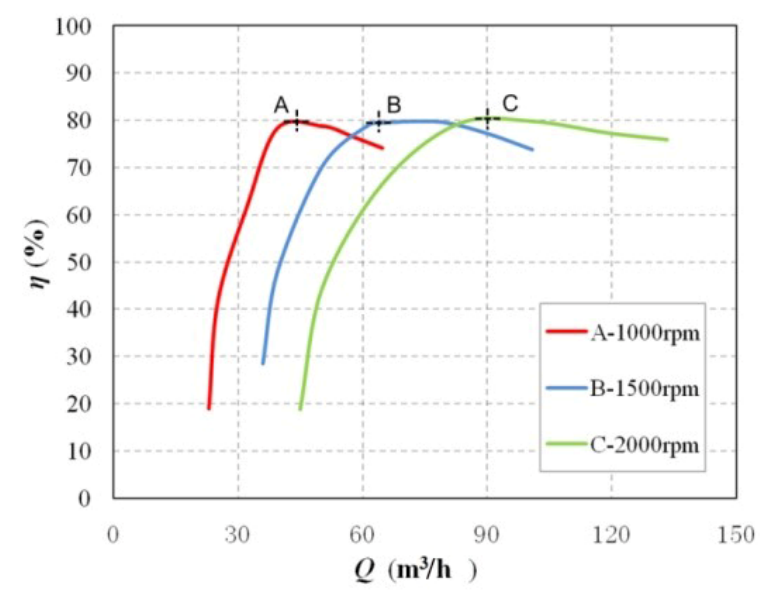

Figure 4. Performance curves of turbine by test.

\subsection{Theoretical Analysis}

The velocity triangle of turbine rotors reflects the flow ability and turbine performance directly. From the Euler turbine energy equation $H_{\mathrm{t}}=\left(u_{1} v_{\mathrm{u} 1}-u_{2} v_{\mathrm{u} 2}\right) / g$, the theoretical head $H_{\mathrm{t}}$ mainly depends on the inlet velocity profiles $v_{\mathrm{u} 2} \approx 0$. Figure 5 shows the rotor velocity triangles. Particularly, the flow angles $\alpha_{1}$ between $v_{1}$ and $u_{1}$ are constant since the absolute inlet velocity and upstream geometry parameters are constant, the differences from flowrates lead to various $w, v_{\mathrm{u} 1}$, and a little deviation on their angles, and the larger flowrate and rotation speed result in the larger incidence angle $\beta_{1 \mathrm{C}}>\beta_{1 \mathrm{~B}}>\beta_{1 \mathrm{~A}}$.

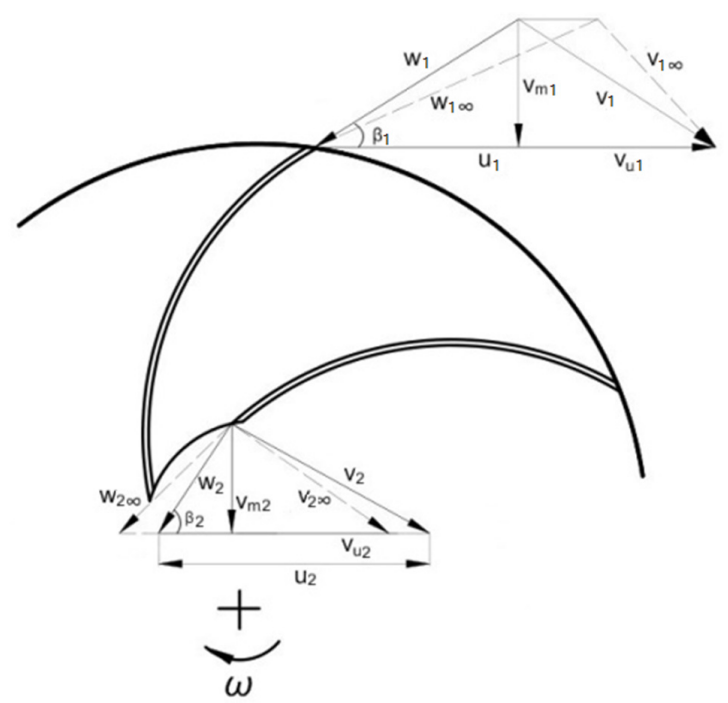

(a) Turbine rotor velocity triangle profile in limited blade slip.

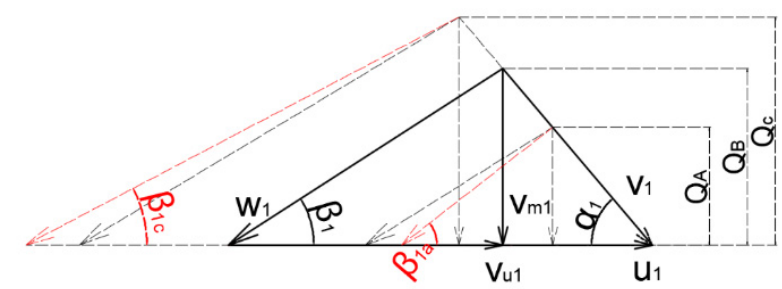

(b) Inlet velocity triangle as various rotation.

Figure 5. Turbine rotor triangle velocity.

The deviation of $\beta_{1}$ influences the axial vortex of rotor channels to a certain degree. From the existing consensus [22], there are comprehensive flows in the rotating channel, as Figure 6 shows, one is a certain scale of circle flow because of the blade rotation, and the 
other is the radial flow by mass conservation. In fact, the inlet flow parameters influence more, and the relative value of $\beta_{1}$ will lead to different scales of the velocity slide in flow channels. By the equation of slide factor, larger $\beta_{1}$ causes larger $\sigma$ or vortex scale given the constant other parameters.

$$
\sigma=1-\frac{\pi}{z} \sin \beta_{1}
$$

Hence,

$$
H_{t}=\frac{u_{1}}{g}\left(\sigma u_{1}-\frac{v_{m 1}}{\tan \beta_{1}}\right)
$$

Substituting Equation (1) into Equation (2), $H_{\mathrm{t}}$ is expressed as:

$$
H_{t}=C_{1}-C_{2} \sin \beta_{1}-\frac{C_{3}}{\tan \beta_{1}}
$$

whereas $C_{1}=\frac{u_{1}}{g}, C_{2}=C_{1} \cdot \frac{\pi}{z}, C_{3}=C_{1} \cdot v_{m}$.

Taking the derivative, $H_{t}^{\prime}=-C_{2} \cos \beta_{1}+C_{3}\left(\sin \beta_{1}\right)^{2}$. Considering the varying ranges of $\beta_{1} \in\left(20^{\circ}, 40^{\circ}\right), \mathrm{z}=4 \sim 7, V_{\mathrm{m}}<V_{\mathrm{in}}=3 \sim 4 \mathrm{~m} / \mathrm{s}$, it can conduct $H_{t}^{\prime}>0$, namely, $H_{\mathrm{t}}$ and $\beta_{1}$ are in an inverse proportion. When flow angle is $\beta_{1 \mathrm{c}}<\beta_{1 \mathrm{~b}}<\beta_{1 \mathrm{a}}$, there will be $H_{\mathrm{tc}}>H_{\mathrm{tb}}>H_{\mathrm{ta}}$. For a fixed rotor geometry, the large flowrate deviation tends to a little enhancement of hydraulic performance. In fact, the leakage of the bilateral chambers of rotors is another reason for the difference of the internal flow structures and flow stability, still that is ignored in the theoretical analysis.

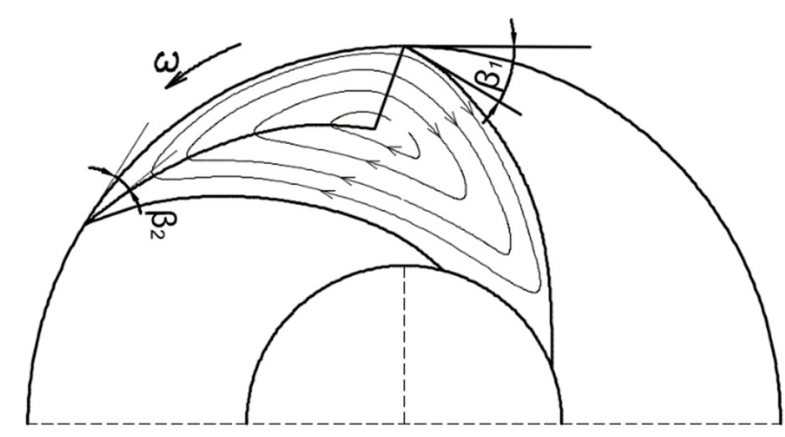

Figure 6. Turbine circumferential vortex diagram.

\section{Numerical Procedure}

\subsection{Mesh Generation}

The computational domain is displayed in Figure 7a. The leakage from the rotor bilateral chambers was taken into consideration. There were five components as follows: suction pipe, volute (including the gap region), rotor, bilateral chambers, and draft tube. To reduce the influence from possible backflow in the inlet and outlet position, the length of suction and discharge domains were extended to three times of the pipeline diameter.

ICEM CFD software (The Integrated Computer Engineering and Manufacturing code for Computational Fluid Dynamics) was applied to create the three-dimensional structured multi-blocks, and for each sub-domain the hexahedral blocks with the respective dimensions were generated to control the grid parameters such as the thickness of the viscous layer (the non-dimensional normal distance from the surface $\mathrm{y}^{+}<50$ ) and the mesh growth ratio. Grids in the special regions were refined and densified as well, such as the leading edges, the trailing edges, and volute tongue. Grid dependence test indicated the turbine head would keep stable when the total mesh number reached 1.5 million. The final mesh number for simulation was 1.76 million: volute 539,564, rotor 652,123, bilateral chambers 253,085 , and inlet and outlet 317,295 , respectively. The general appearance of the meshing is displayed in Figure $7 \mathrm{~b}$. 


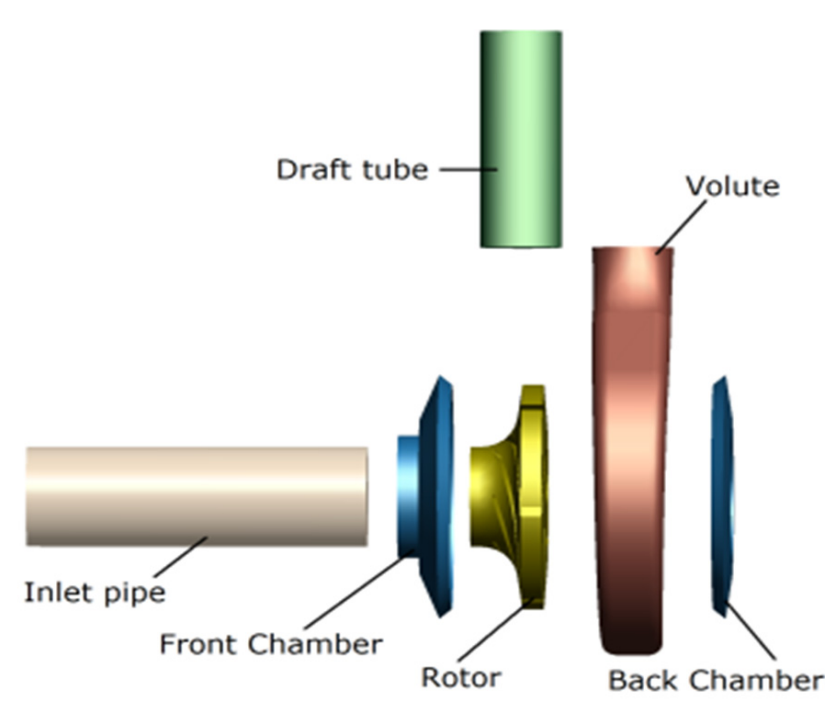

(a)
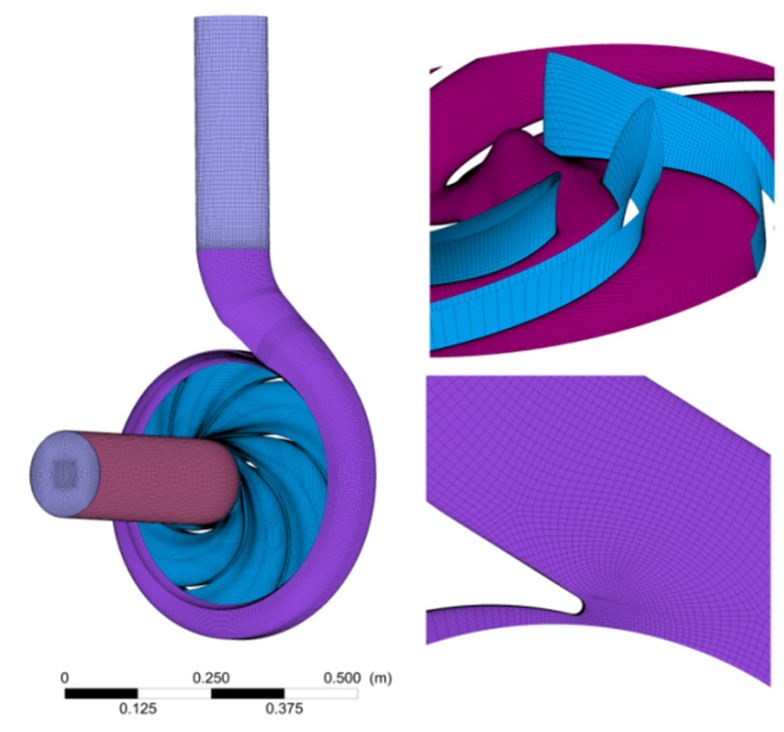

(b)

Figure 7. (a) 3D mode of whole flow domains; (b) meshing display.

\subsection{Solution Parameters}

The commercial CFD code CFX was used to solve the governing equations. The fluid material was clear water at $20^{\circ} \mathrm{C}$. The widely accepted boundary conditions of inlet mass flow and the outlet pressure were used for the simulation of turbine, and the boundary details of A, B, and C are listed in Table 2. Large eddy simulation was performed for the forced turbulence flow in the channels inside, thus vortex of different scales could be captured. Second-order discretization was used for the convection terms and central difference schemes for the diffusion terms. The roughness of wall was $50 \mu \mathrm{m}$. The convergence criterion was $10^{-5}$.

Table 2. Boundary conditions of A, B, and C points.

\begin{tabular}{cccc}
\hline Item & Inlet & Outlet & Rotation \\
\hline $\mathrm{A}$ & $Q=12.5 \mathrm{~kg} / \mathrm{s}$ & $\mathrm{P}=1 \mathrm{~atm}$ & $1000 \mathrm{rpm}$ \\
$\mathrm{B}$ & $Q=17.5 \mathrm{~kg} / \mathrm{s}$ & $\mathrm{P}=1 \mathrm{~atm}$ & $1500 \mathrm{rpm}$ \\
$\mathrm{C}$ & $Q=25.0 \mathrm{~kg} / \mathrm{s}$ & $\mathrm{P}=1 \mathrm{~atm}$ & $2000 \mathrm{rpm}$ \\
\hline
\end{tabular}

Steady CFD calculations were carried out and the results were used as the initial condition of unsteady simulation. The choose of time step agreed with Courant number criterion (Equation (4)). According to the iterative calculation in Fluent, the final time steps for $\mathrm{A}, \mathrm{B}$, and $\mathrm{C}$ were $1.67 \times 10^{-4} \mathrm{~s}, 1.11 \times 10^{-4} \mathrm{~s}$, and $8.33 \times 10^{-4} \mathrm{~s}$, separately corresponding to $1^{\circ}$ of a rotor passing angle $[16,17]$. The total time was nine rotor revolution periods and the last three revolutions data were extracted and analyzed.

$$
\text { Courants }=\frac{\Delta t \cdot\left|v_{\text {fluid }}\right|}{l_{\text {cell }}} \leq 20
$$

where $\left|v_{\text {fluid }}\right|$ was the absolute value of fluid characteristic velocity and $l_{\text {cell }}$ was the characteristic size of fluid grids cell. 


\section{Result and Discussion \\ 4.1. Velocity Distribution in Rotor and Volute}

The internal flow fields were displayed by further CFD-Post, we made efforts to reveal a relationship between the flow and turbine vibration. Figure 8 shows the pressure and velocity streamlines distribution of isosurface, the pressure profiles of different BEP points are generally similar, the pressure deviation on radial direction takes place at the downstream locations in volute, and the significant pressure gradient appears inside rotor passage along the flow direction. The difference of velocity is mainly embodied in changes of streamlines direction and the circumferential vortex at the blade leading edge and nearby downstream position. There are serious flow vortexes in channel 1 and 2 in the partial point (A and $\mathrm{C}$ ) with the pressure gradient towards the flow direction, especially in the leading-edge pressure side; for the design condition $\mathrm{B}$, the pressure gradient is in the circumferential direction. Overall, circumferential vortices of volute become weaker in the downstream (channels 4,5, and 6) than the upstream (channels 1,2, and 3), with the exception of flow channels 4 and 5 , the turbulent flow means the local low-pressure area and differentiation of axial-surface velocity, and also weakens the flow passing capacity of the channel to some extent.

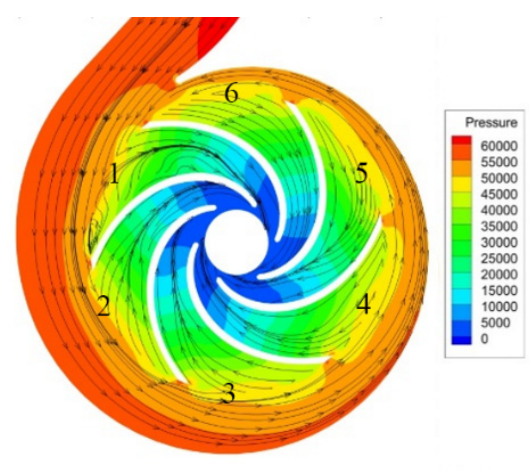

(a) A point

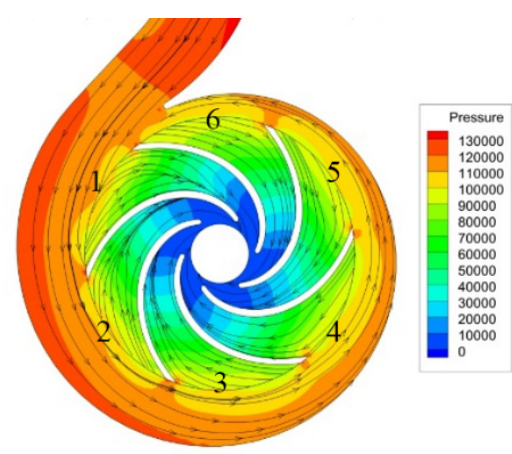

(b) B point

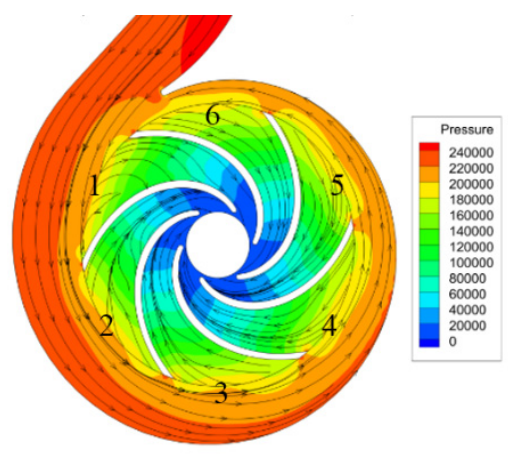

(c) C point

Figure 8. Pressure and streamlines of isosurface.

Figure $9 \mathrm{a}-\mathrm{c}$ show the axial profiles of the velocity distribution at turbine tongue position; the flow structures of different points are very close. The bilateral chambers contribute to the flow construction of the mainstream greatly, where the velocity is much lower and obvious vortex exists in the relative isolated space. The symmetrical secondflow is significant in the cross-section of volute; when it flows into the rotor, the kinetic energy begins to work, velocity decreases, and the local vortex always occurs in the middle channel near the hub and shroud side. The vortex position and scale are a little different for various working points. Figure $9 \mathrm{~d}-\mathrm{f}$ show the distribution of the axial flow field at the 8 th section of the volute. Each point shows serious second-flow in volute, flow in the center is circumferential, and eddies surrounding the diffusion zone. Fluid into the bilateral is relatively less than the tongue section. Channel vortex takes place at the very beginning, and the whole flow distribution is consistent at $\mathrm{A}, \mathrm{B}$, and $\mathrm{C}$ points. 


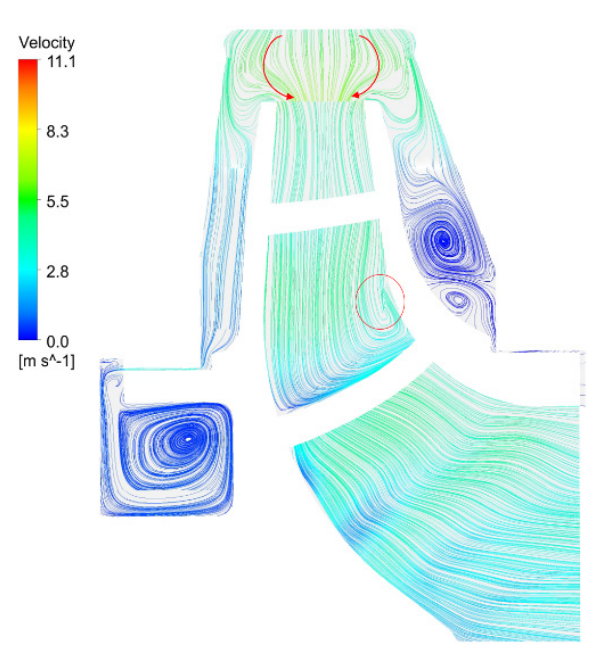

(a) Volute tongue for $\mathrm{A}$

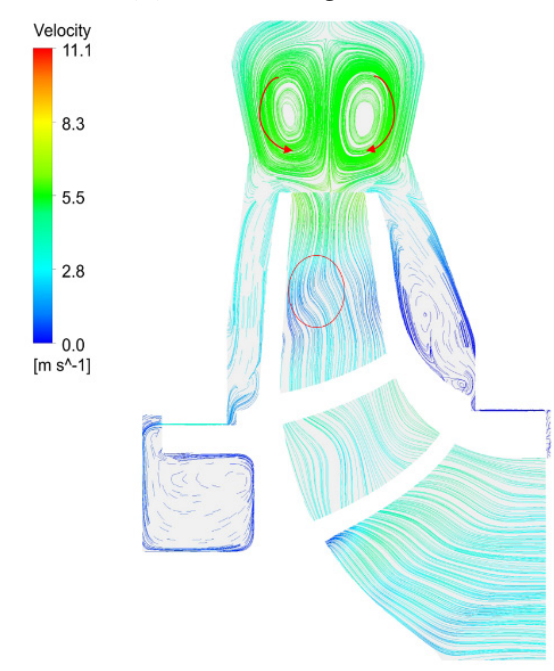

(d) Volute Section VIII for A
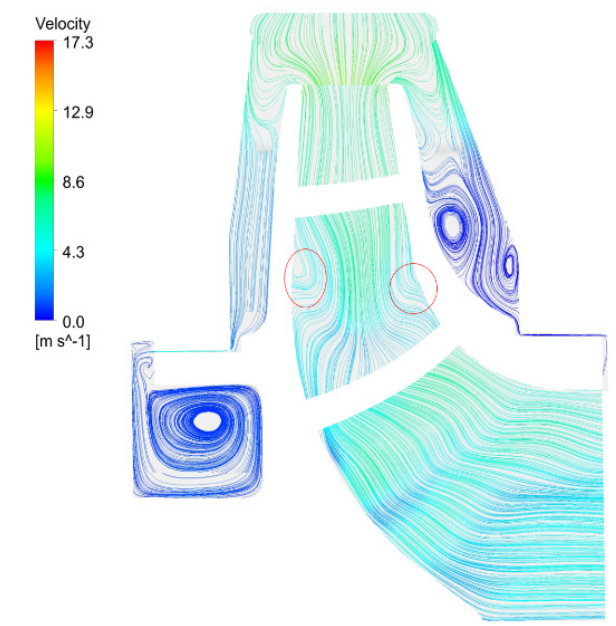

(b) Volute tongue for B
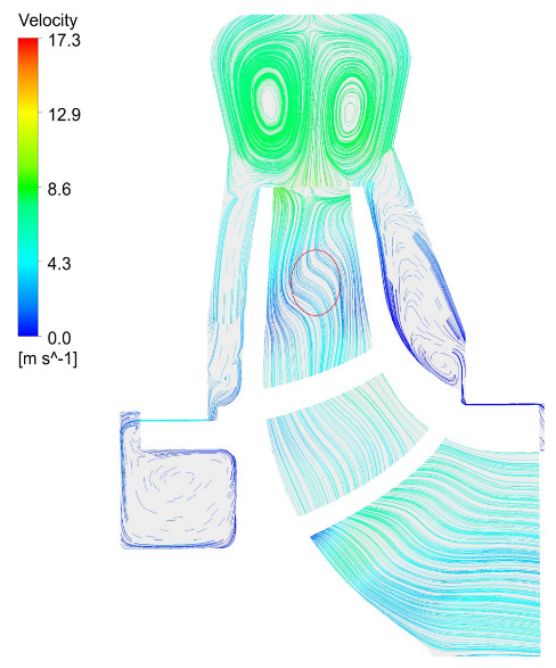

(e) Volute Section VIII for B

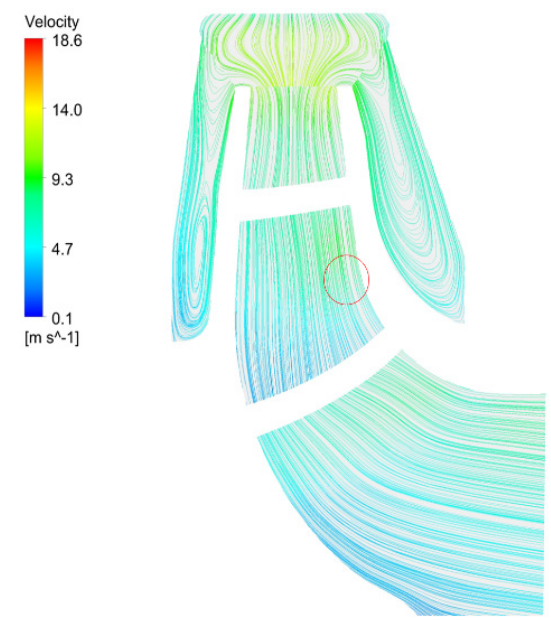

(c) Volute tongue for $\mathrm{C}$
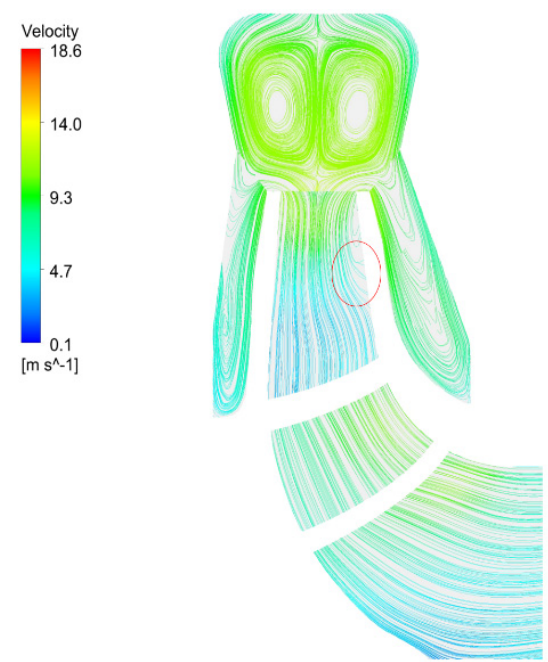

(f) Volute Section VIII for C

Figure 9. Flow profile of rotor axial surface and volute section VIII.

\subsection{Pressure and Hydraulic Load in Rotors}

Turbine rotor converts fluid energy, and the magnitude and distribution of blade load, therefore, reflect the amount of output power. Figure 10a shows the pressure profile of pressure side (PS) and suction side (SS) in the A, B, and C conditions. From A to C, static pressure of both the two sides increases significantly, as well as the whole blade load. The pressure near the leading edge differs observably among different rotations. Blade pressure decreases with flow direction. In the location of $0.94, P_{P S}$ and $P_{S S}$ become zero simultaneously, and decrease to be negative value near the trailing edge. As for the absolute blade load, the range (streamline 0.02 0.94) works positively, and the bilateral works negatively. Figure $10 \mathrm{~b}$ shows the normalized pressure by $P^{*}=P /\left(0.5 \rho u_{2}^{2}\right)$; the pressure tendencies of various points are very similar, even the magnitudes of $P_{S S}$ are almost equal. The main deviation occurs on $P_{p s}$ near the blade leading edge; $P_{p s}$ at $\mathrm{B}$ is significantly smaller than A and $C$, that is just the issue of flow matching between blade geometry and incidence parameters mentioned in Section 2.2. 


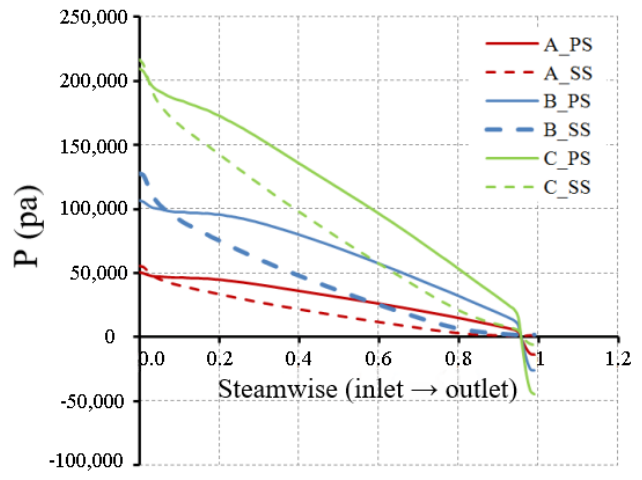

(a) Blade load

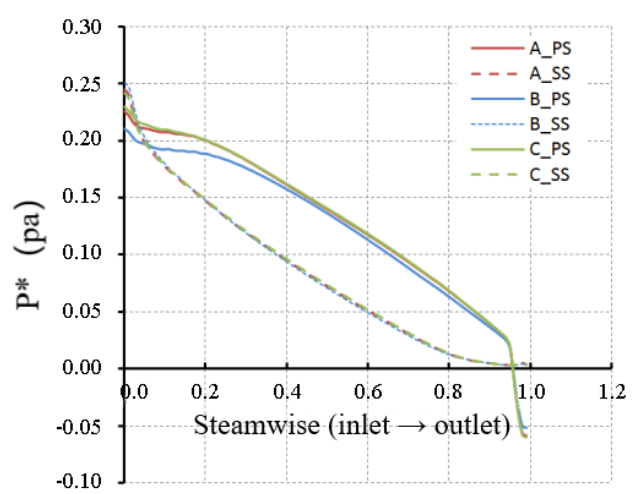

(b) Normalized blade load

Figure 10. Blade load of various best efficiency points (BEPs).

In this paper, the circumferential pressure variation (from PS to SS) in the impeller passages are monitored, as Figure 10 shows. The abscissa is the radial position of the runner (perpendicular to the streamline direction), and the ordinate is the pressure. On the whole, the pressure of the radial boundary decreases from the PS to SS, since the blade rotates and works. In theory, the pressure will drop uniformly if circumferential slip and vortex of the fluid are not taken into consideration. In Figure 11a, the curves have different pressure gradients in the blade inlet position. Obviously, the trend of working condition $\mathrm{B}$ is the closest to linearity, followed by $\mathrm{C}$, and the deviation of $\mathrm{A}$ is the largest. The flow turning points takes place at the position a little larger than $0.4 \mathrm{~L}$ ( $\mathrm{L}$ is the cross-section line), whereas the pressure drop on both sides is steep, and the flow field structure is different, to a certain degree. Combined with the velocity contour above, it can be judged that there are always local vortexes of a certain scale on the inner side and a significant radial cross-flow on the outer side, with uneven distribution of radial flow and velocity. In Figure 11b, the transition point appears at $0.625 \mathrm{~L}$, which indicates a migration of mainstream trajectory from PS to SS, compared with suction position. The pressure fluctuation of $B$ and $C$ after the transition point may result from the flow deflection of upstream direction since there is no obvious vortex, while the pressure drop of $\mathrm{B}$ under the same condition is closer to the trend line, indicating a more uniform flow structure. To be noted, the pressure drop range varies from 0.86 to 0.55 in the inlet position, and that shrinks to $0.34 \sim 0.41$; the radial gradient of inlet position is much larger than the middle position.

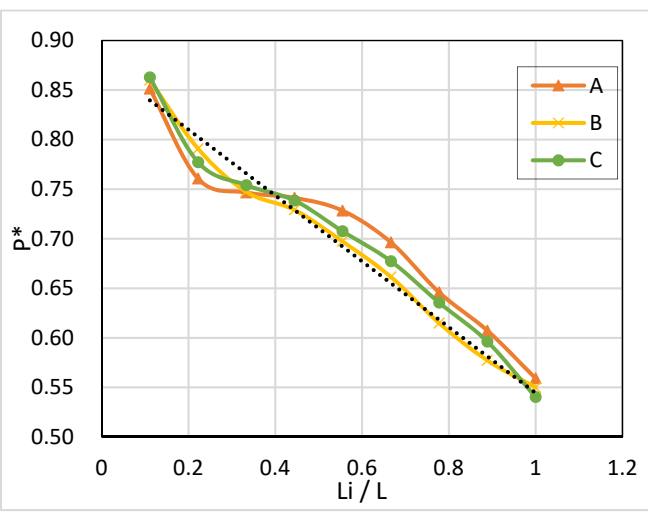

(a) The leading-edge position

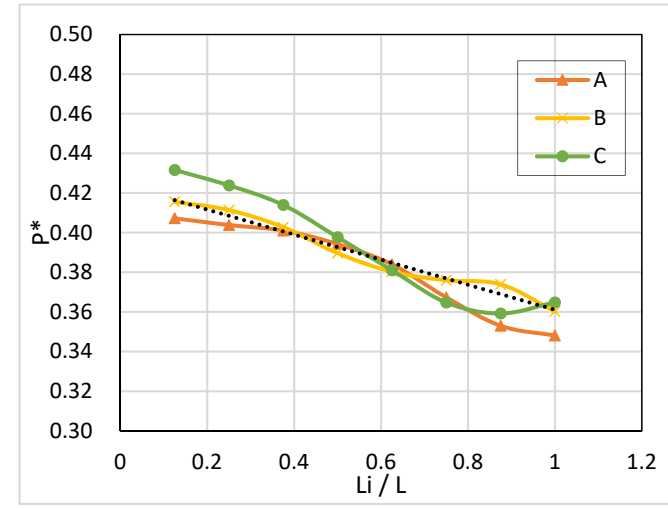

(b) The middle position

Figure 11. The circumferential pressure decreases in the rotor channel.

The figure below shows the flow distribution in different impeller channels at a stable moment. It can be seen from Figure 12 that the channels with less flowrate are 1, 2, and 5, and their physical characteristics are the adjacent position downstream of the volute tongue 
and the second flow channel downstream. The large flowrate channels take place at channel 6 right opposite the volute tongue, and channel 3 of the middle channel. The flowrate of other channels appears as an interlacing distribution fluctuating around the average line 0.166 . From the figure, flowrate distribution at larger flowrate point $C$ is more stable than $\mathrm{A}$ and $\mathrm{B}$. In essence, this hydraulic parameter is related with stator-rotor interaction, the radial gradient of fluid crossing velocity in volute, and the gap flow between rotor and stator. Based on this consideration, the channels 1 and 2 easily take place in the impeller vortex, especially in the low flowrate point, while the flow will be improved in channel 6 as the flow energy attenuates both in volute and gap region.

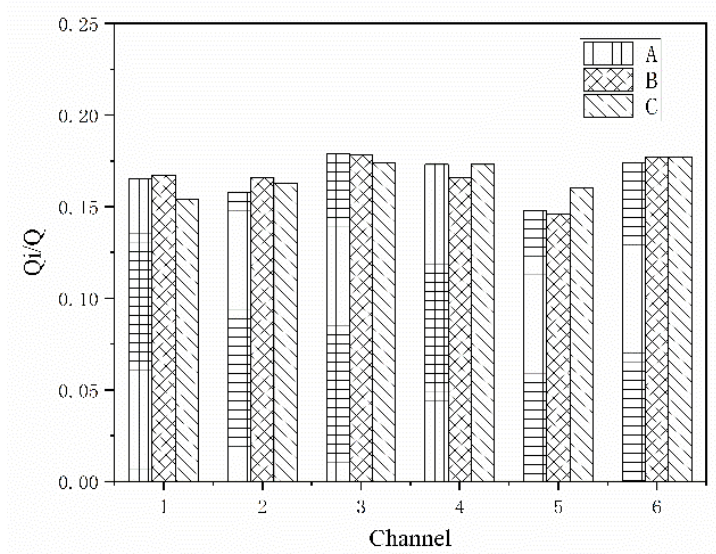

Figure 12. Flowrates distribution among rotor channels.

\subsection{Pressure Fluctuation in Volute and Impeller}

The location of pressure monitoring points was displayed in Figure 13.

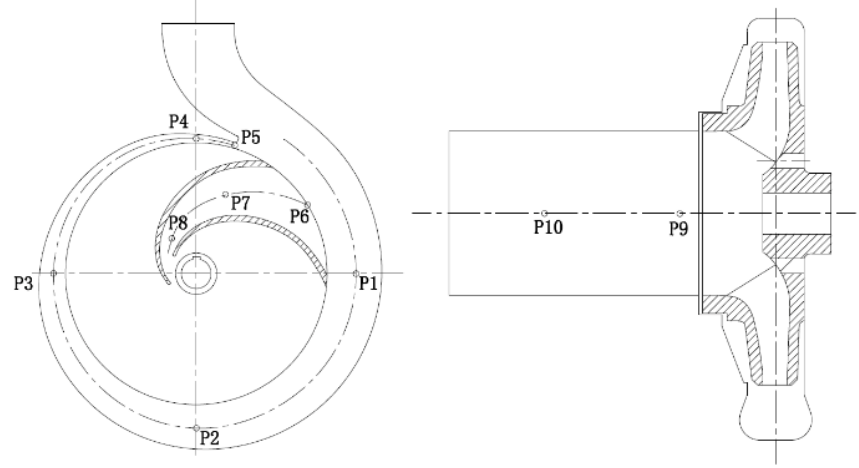

Figure 13. Location of pressure monitoring points.

Figure 14 shows pressure pulsation in volute domain, where $C_{p}$ represents the definition of pressure pulsation coefficient:

$$
C_{p}=\frac{P-\bar{P}}{0.5 \rho u_{2}^{2}}
$$

where $\bar{P}$ is the time-averaged pressure. 


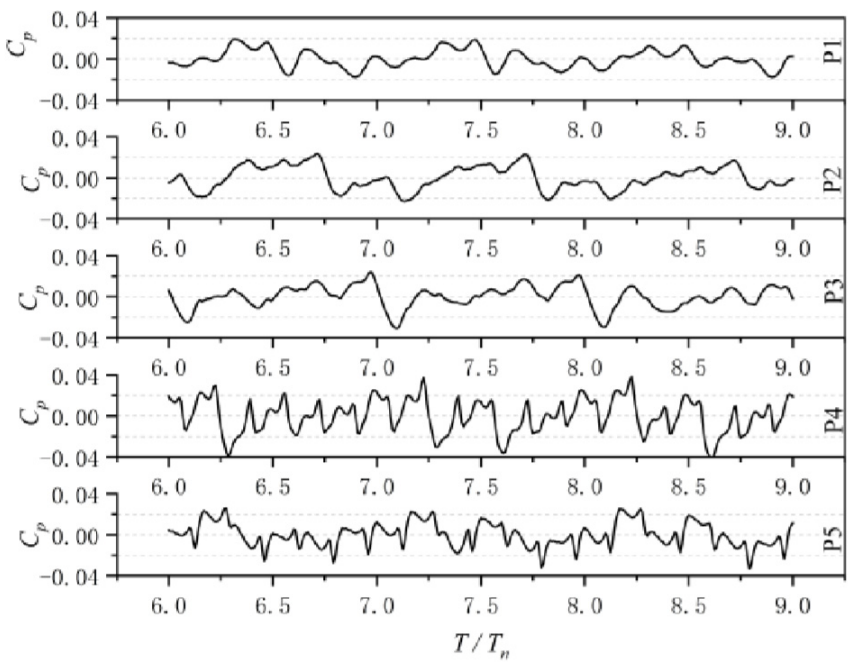

(a) A point.

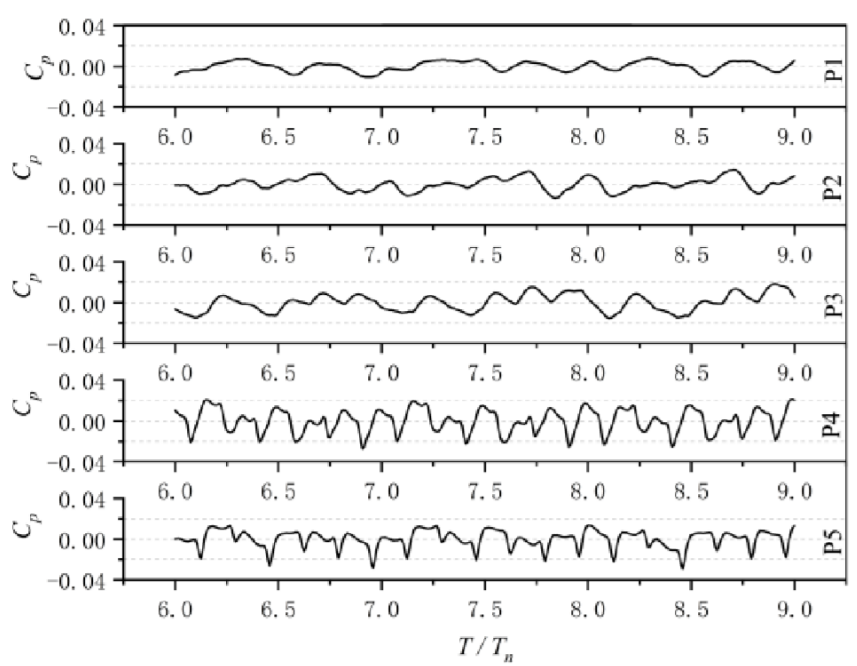

(b) B point.

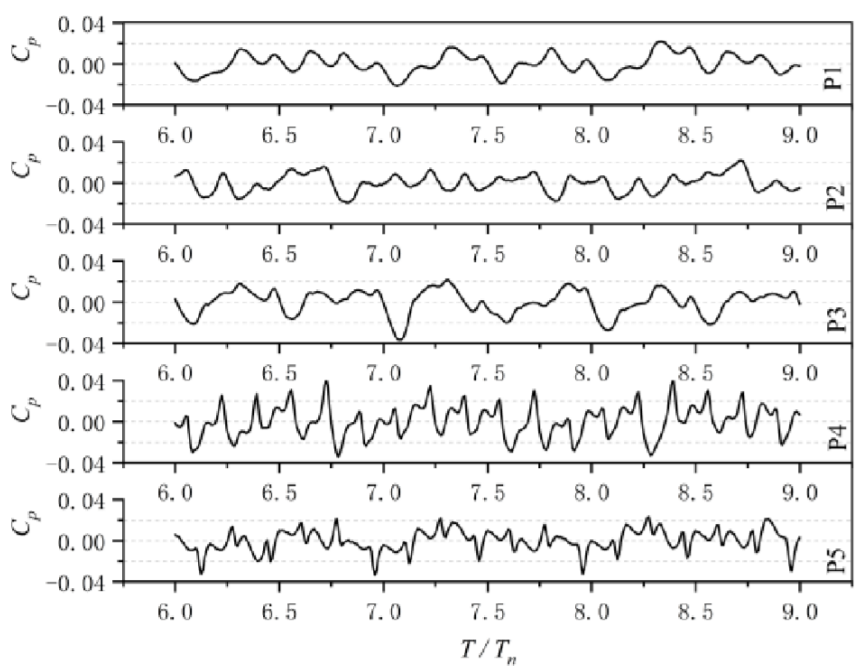

(c) C point.

Figure 14. Pressure time domain in the volute.

As indicted, pressure distribution of volute appears in a certain periodic trend, the pulse of a certain flowrate point intensifies gradually from $P 1$ to $P 5$, and both the pressure 
amplitude and the variation frequency. Comparing different working points, there are two significant features: pressure amplitude of B is much lower than A and C, especially for points 1,2 , and 3 of the upstream regions of volute, and the pressure variation frequencies of $A$ and $C$ are larger than B, particularly for points 4 and 5 near the volute tongue location. By associating the physical hydraulic model and the internal flow distribution, a sense can be obtained that pressure load in volute will be exacerbated when flowrate and head pressure deviate from the designed points, and the flow and pressure fluctuation along the flow direction in volute is different, since the unsteady flow-induced flow instability aggravates from upstream to downstream and the most turbulent place occurs in volute tongue. In the deviation cases, the degree of flow turbulence and fluctuation is more serious in addition.

By fast Fourier transform (FFT), the frequency domain of pressure fluctuation from the time domain can be obtained, as shown in Figure 15 (the typical locations of P5 are selected). The fluctuations of various working points keep synchronous, the dominant pulsations are composed by two sources: one is the abundant low-frequency pulses caused by transient flow migration, flow-wake, and second flow, the other is the blade passing frequency $\left(6 F_{n}, F_{n}\right.$ is rotor passing frequency) and its multi-frequency caused by the rotorstator interaction. The most intense pulsation occurs in the low-frequency area, while the high-order frequency area (after $17.95 F_{n}$ ) tends to be weak. Amplitudes of $\mathrm{A}$ and $\mathrm{C}$ are obviously larger than that of $\mathrm{B}$ at the same monitor point and pulse frequency. Pulsation curve of A seems generally more intense than $C$, but the behavior of peak points is opposite.

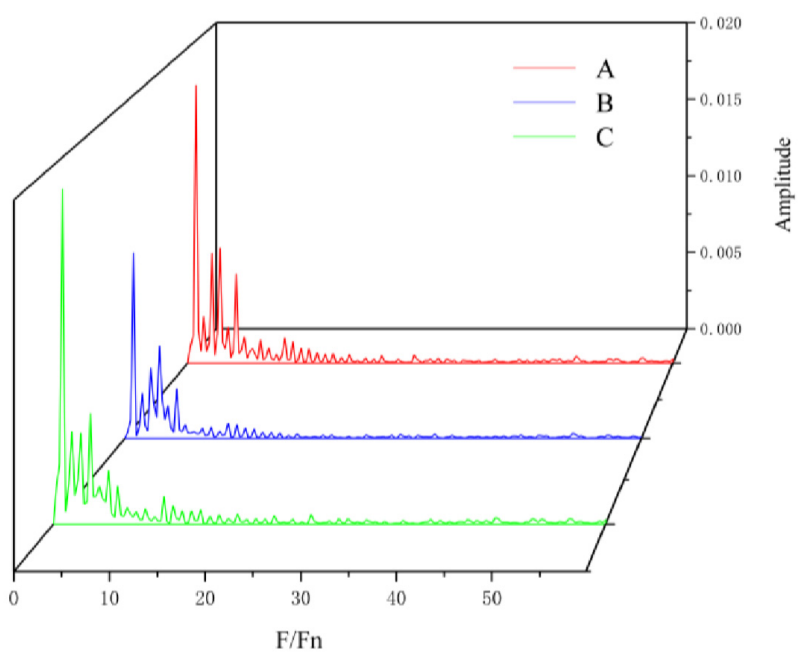

Figure 15. Pressure frequency of P5 (volute tongue) in the volute.

Figure 16 exhibits the pressure distribution of the three points in the rotor domain. It shows that, in the same condition, the pressure at position P6 and P7 fluctuates more intensely, it reduces significantly at $\mathrm{P} 8$, and the pulse amplitude of $\mathrm{B}$ condition is much lower that of A and C. By FFT, the frequency domain in rotor is shown is Figure 17, a lot of irregular pulses exist in the frequency range of $0-5 F_{n}$, and the main frequency is still the blade-passing frequency and its multi-frequency. 


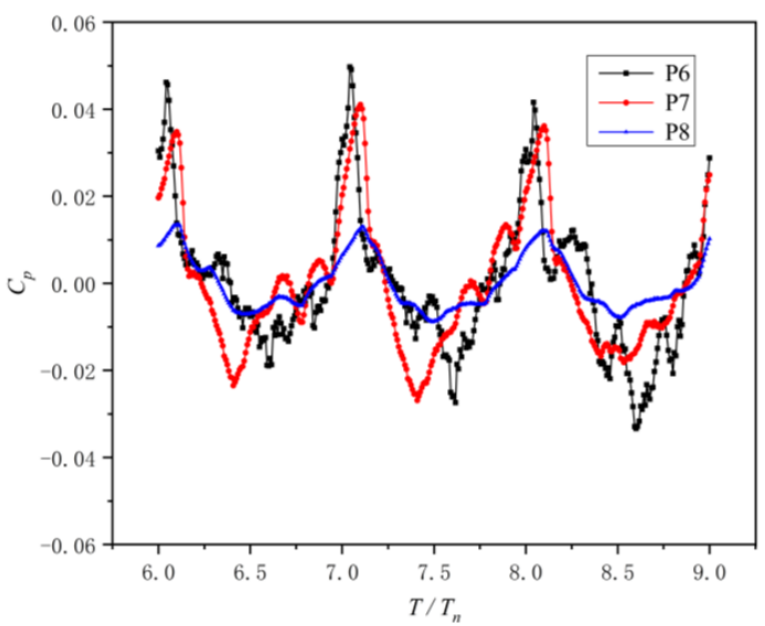

(a) A point.

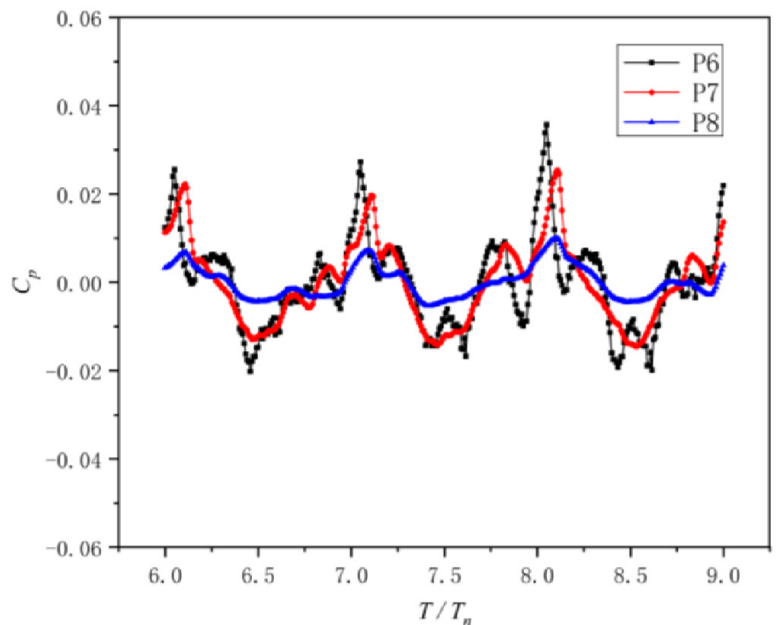

(b) B point.

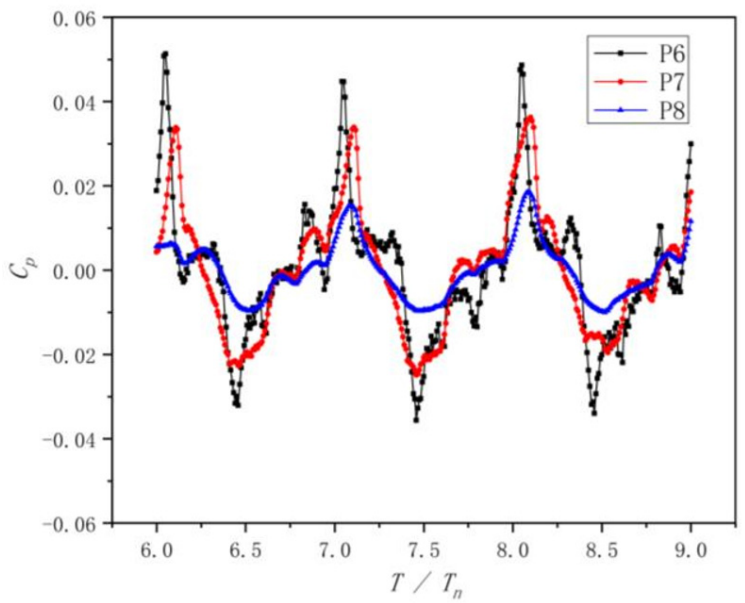

(c) C point.

Figure 16. Pressure time domain in the rotor. 


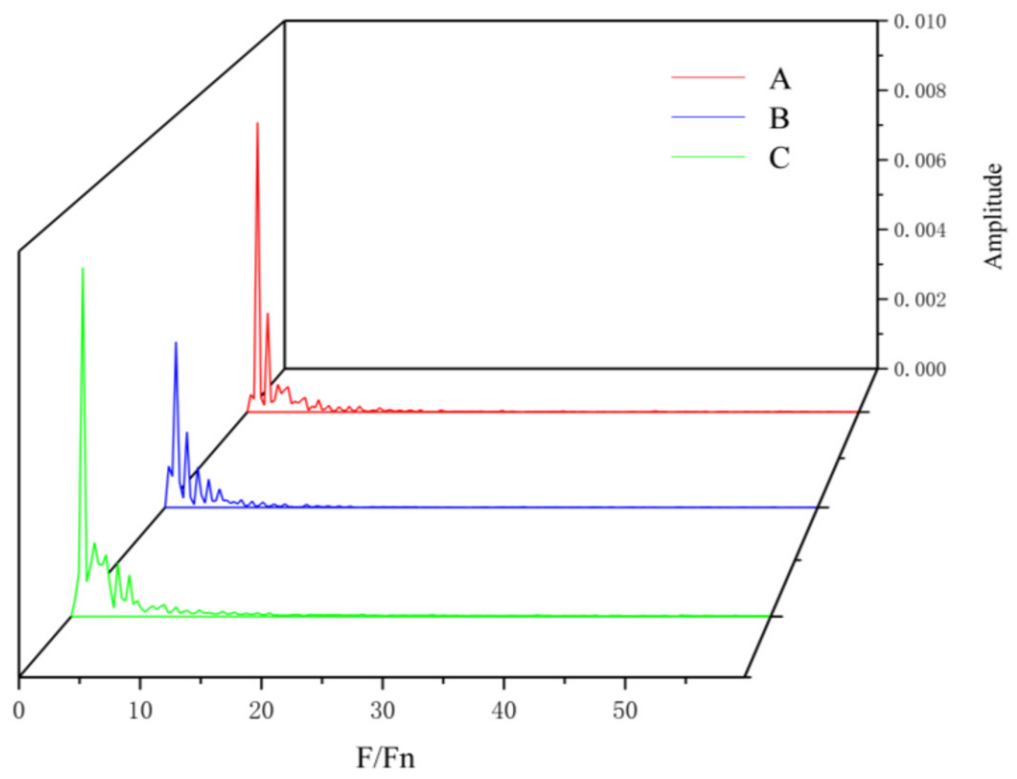

Figure 17. Pressure frequency of $\mathrm{P} 8$ in the rotor.

\section{Experimental Setup and Validation}

A turbine open test ring was established, as shown in Figure 18. A pressurizing pump generating high-energy fluid drove a centrifugal turbine, which drove a new co-axial load. The hydraulic performance and vibration experiments were performed on the ring.

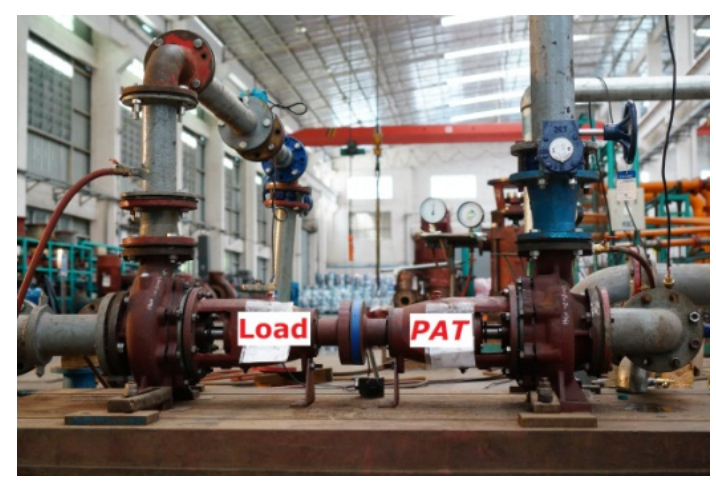

Figure 18. Test ring.

In flow measurement, pressure sensors were used to test the inlet and outlet pressure of the turbine (in order to facilitate field operation, the mechanical pressure gauge was installed), so as to obtain the turbine head. The flowmeter was an electromagnetic flowmeter. The torque meter was connected between the turbine and the load, thereby obtaining the speed and torque. Therefore, the head, flowrate, and power information of the turbine could be known, and the efficiency could be further calculated, simultaneously all the measuring instruments met the high accuracy $(\leq 3 \%)$. After the pressure, flowrate, rotation speed, and shaft torque were acquired, the performance characteristics could be obtained. By adjusting the discharge valve and import bypass valve, the turbine could be regulated to work in the required conditions; the performance curves of $A, B$, and $C$ points are shown in Figure 4 and Table 3. 
Table 3. BEPs experimental validation of performance parameters.

\begin{tabular}{cccccc}
\hline Item & $\boldsymbol{n} \mathbf{( \mathbf { p p m } )}$ & $\boldsymbol{Q}\left(\mathbf{m}^{\mathbf{3}} \mathbf{h}\right)$ & $\boldsymbol{H} \mathbf{( m )}$ & $\boldsymbol{P ( \mathbf { k W } )}$ & $\boldsymbol{\eta} \mathbf{( \% )}$ \\
\hline A-Test & 1000 & 44.6 & 7.0 & 0.68 & 79.5 \\
A-CFD & 1000 & 45.0 & 7.2 & 0.73 & 82.8 \\
B-Test & 1500 & 63.4 & 14.1 & 1.94 & 79.8 \\
B-CFD & 1500 & 63.0 & 14.8 & 2.10 & 82.5 \\
C-Test & 2000 & 89.8 & 27.1 & 5.32 & 80.3 \\
C-CFD & 2000 & 90.0 & 28.0 & 5.70 & 83.1 \\
\hline
\end{tabular}

We considered the volumetric losses $\left(\eta_{V}=\left(Q_{t}-Q_{l}\right) / Q_{t}, Q_{l}\right.$ is the leakage capacity obtained by CFD) and the disc friction losses of rotor shroud $\left(P_{f}=M \cdot \omega, M\right.$ is the friction torque, gained by CFD), in the data processing. The numerical calculation and experimental results are in good agreement, and Table 3 shows the corresponding performance parameters of A, B, and C. The numerical head and efficiency are closed to the experiment; while the useful work of CFD is slightly larger, the main reason is that the power losses of bearing and mechanical seal cannot be calculated by simulation. The relative errors of turbine efficiency are separately $4.2 \%, 3.4 \%$, and $3.5 \%$ at the three points, which proves the numerical results are credible.

The influences of hydraulic fluctuation can be transferred to the flow components by excitation vibration, and the final effects are the structural vibration and noises [18]. Based on this consideration, the vibration characteristics of turbine were monitored to indirectly validate turbine hydraulic pulsation characteristics. The measuring equipment is the Yiheng Mi-7004 data collection and analysis system with the accuracy of $\pm 3 \%$. Figure 19a reflects the location of monitoring points, where M1 is in the turbine base (horizontal), M2 is in the middle suspension (vertical), and M3 is in the location of bearing box (axial); Figure 19b is the installation view of vibration sensors; and Figure 19c-e are the appearances of data collection and analysis devices, three-directional sensor, and onedirectional sensor. Table 4 lists the results of vibration test, containing the information of vibration displacement, vibration intensity, and acceleration, while the vibration intensity $v_{\mathrm{r} \cdot \mathrm{m} \cdot \mathrm{s}}$. reflects the grade and energy of vibration with its definition as follows:

$$
v_{\text {r.m.s. }}=\sqrt{\frac{1}{T} \int_{0}^{T} v^{2}(t) \mathrm{dt}}
$$

where $v(\mathrm{t})$ is time-relied vibration velocity, $T$ is the sampling time, and $v_{\mathrm{r} \cdot \mathrm{m} \cdot \mathrm{s}}$ is the root mean square (RMS) of the vibration velocity.

The relationship of vibration intensity of various locations in a same point is M3 > M1 > M2, which indicates that the axial vibration is more intensive than the other two directions. By comparing vibration intensity of the same position and various working point, it can indicate the rules of $\mathrm{C}>\mathrm{A}>\mathrm{B}$. Moreover, vibration displacement and acceleration exhibit that the similar distribution, experimental vibration results, and numerical pressure pulsations are consistent overall. 


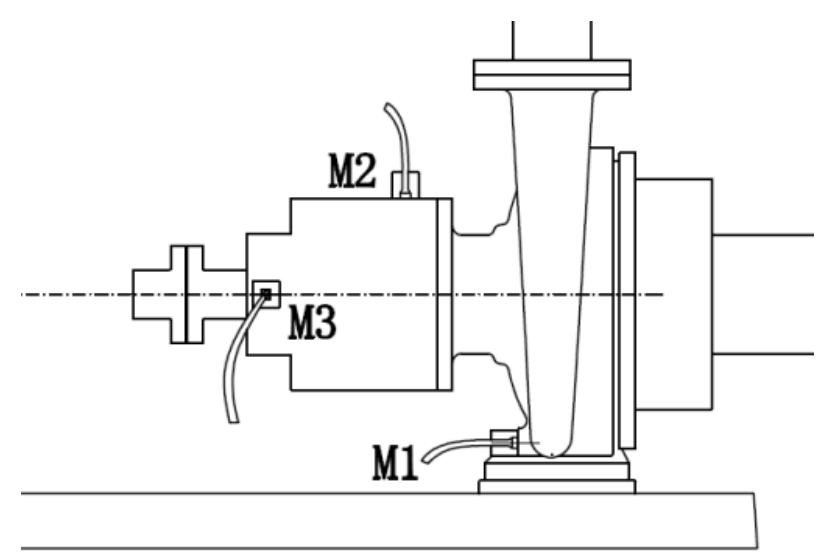

(a) Monitoring points configuration.

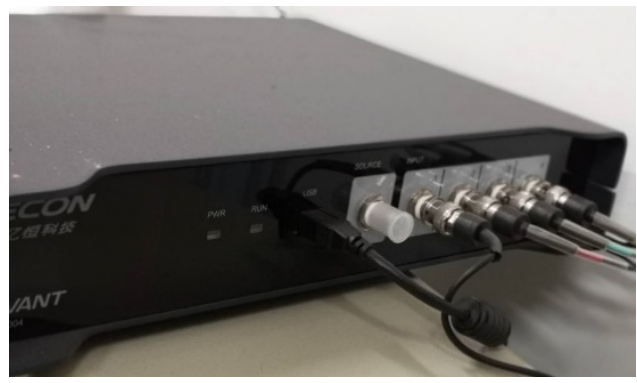

(c) Data collection and analysis devices.

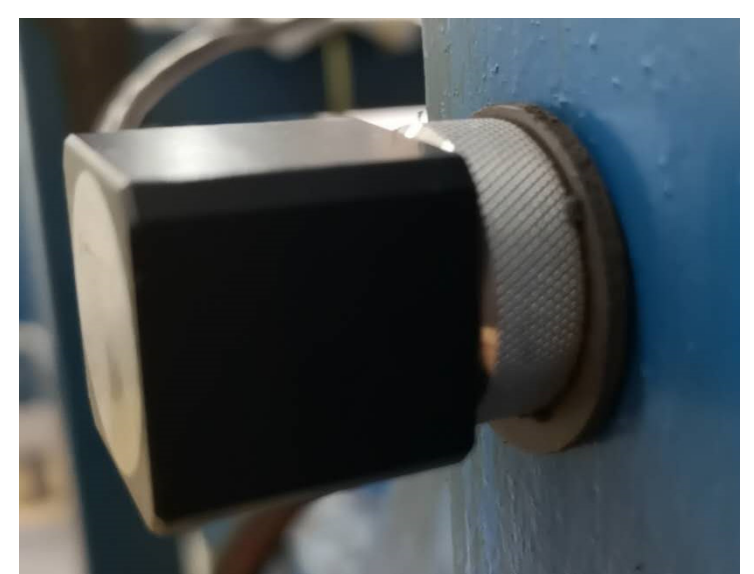

(b) Installation view of vibration sensors.

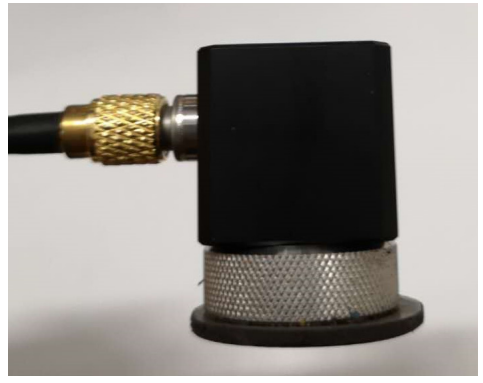

(d) Three-directional sensor.

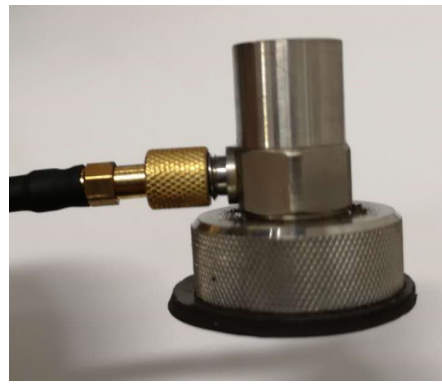

(e) One-directional sensor.

Figure 19. Monitoring locations of vibration test.

Table 4. Time-averaged BEPs vibration data.

\begin{tabular}{cccc}
\hline Item & Displacement $(\boldsymbol{\mu m})$ & Intensity $(\mathbf{m m} / \mathbf{s})$ & Acceleration $\left(\mathbf{m m} / \mathbf{s}^{\mathbf{2}}\right)$ \\
\hline A-M1 & 12 & 1.4 & 4.1 \\
A-M2 & 10 & 0.8 & 1.6 \\
A-M3 & 21 & 2.5 & 5.0 \\
B-M1 & 11 & 1.1 & 3.8 \\
B-M2 & 10 & 0.7 & 1.5 \\
B-M3 & 17 & 2.3 & 4.4 \\
C-M1 & 14 & 1.8 & 4.5 \\
C-M2 & 11 & 0.9 & 2.2 \\
C-M3 & 23 & 2.9 & 5.1 \\
\hline
\end{tabular}

\section{Conclusions}

This paper firstly focuses on the issue of turbine various BEPs selection and their external flow mechanism; the whole structure was performed from the aspects of the hydraulic performance, flow stability, blade load, and the unsteady hydraulic pulsation, etc., to comprehensively expound the internal flow and external characteristic differences of different BEPs. The calculation and analysis confirmed the performance and vibration experiment.

1. In theory, different BEPs have similar hydraulic performances; because of the differentiated incidence angle and circumferential vortex in rotors, the hydraulic performance will be a little improved in large flowrate BEPs. The bilateral chambers have strong influence on turbine behaviors, in addition.

2. For turbine flow field, the obvious deviations of BEPs are the blade loads near the leading edge and their working ability. Since the existence of circumferential vortex, radial velocity gradient in rotors is different among BEPs, and flow field and rotor channels flowrate distribution present a large flowrate trend. 
3. The pressure pulsation increases with flowrate. It is the incidence angle, circumferential vortex, uneven distribution of channel flowrate, and second flow in volute that cause the flow instability, pressure pulsation, and vibration of the whole machine.

4. From the perspective of actual operation, the design condition, or a slightly lower flowrate is appropriate, larger flowrate point is easier to lead to running instability.

Author Contributions: X.S. and Z.T.; Creativity, Z.C.; method, Z.C. and Z.T.; software, X.S. and Z.T.; verification; Article writing, X.S.; Z.C. and Y.L.; Financial support, X.S.; Y.L. and Y.J.; Test part, X.S.; Y.J. and Y.L.; All authors have read and agreed to the published version of the manuscript.

Funding: This work was supported by NSFC program NO. 51706206 and NO. 5143000396, Postdoctoral Sustentation Fund NO. 2017M622561, and the Key Research and Development Program of Zhejiang Province No. 2019C03117, 2020 C03099.

Institutional Review Board Statement: Not applicable.

Informed Consent Statement: Not applicable.

Data Availability Statement: Not report any data.

Conflicts of Interest: The authors declare no conflict of interest.

\begin{tabular}{|c|c|}
\hline \multicolumn{2}{|c|}{ Abbreviations } \\
\hline$B E P$ & best efficiency point \\
\hline LES & large eddy simulation \\
\hline$D_{1}$ & rotor inlet diameter, $\mathrm{mm}$ \\
\hline$D_{2}$ & rotor outlet diameter, $\mathrm{mm}$ \\
\hline$D_{3}$ & volute base circle diameter, $\mathrm{mm}$ \\
\hline$D_{4}$ & volute outlet diameter, $\mathrm{mm}$ \\
\hline$D_{h}$ & rotor hub diameter, $\mathrm{mm}$ \\
\hline$F_{n}$ & rotor passing frequency, $\mathrm{Hz}$ \\
\hline$F_{x, y, z}$ & rotor thrust of $\mathrm{x}, \mathrm{y}, \mathrm{z}$ direction, $\mathrm{N}$ \\
\hline$H$ & head, $\mathrm{m}$ \\
\hline$M$ & turbine torque output, $\mathrm{W}$ \\
\hline$P$ & turbine power, $\mathrm{W}$; pressure, $\mathrm{Pa}$ \\
\hline$Q$ & flowrate, $\mathrm{kg} / \mathrm{s}, \mathrm{m}^{3} / \mathrm{s}$ \\
\hline$T_{n}$ & rotor revolution period, $s(=60 / n)$ \\
\hline$B$ & rotor inlet width, $\mathrm{mm}$ \\
\hline$d_{2}$ & rotor diameter, $\mathrm{mm}$ \\
\hline$n$ & rotating speed, $\mathrm{rpm}$ \\
\hline$v$ & fluid velocity, $\mathrm{m} / \mathrm{s}$ \\
\hline$y^{+}$ & y plus \\
\hline$z$ & blade number \\
\hline$\sigma$ & slip factor \\
\hline \multicolumn{2}{|c|}{ Greek symbols } \\
\hline$\beta_{1}$ & blade inlet angle, ${ }^{\circ}$ \\
\hline$\beta_{2}$ & blade outlet angle, ${ }^{\circ}$ \\
\hline$\varphi$ & blade wrap angel, ${ }^{\circ}$ \\
\hline$\omega$ & rotation angle, $\mathrm{rad} / \mathrm{s}$ \\
\hline$\eta$ & turbine efficiency \\
\hline \multicolumn{2}{|c|}{ Subscripts } \\
\hline$f$ & friction loss \\
\hline$l$ & leakage \\
\hline r.m.s & root-mean-square \\
\hline$t$ & theoretical \\
\hline$v$ & volumetric \\
\hline $\mathrm{s}$ & suction side \\
\hline $\mathrm{p}$ & pressure side \\
\hline
\end{tabular}




\section{References}

1. Nouni, M.R.; Mullick, S.C.; Kandpal, T.C. Providing electricity access to remote areas in India: Niche areas for decentralized electricity supply. Renew. Energy 2009, 34, 430-434. [CrossRef]

2. Bhattacharya, S.C.; Jana, C. Renewable energy in India: Historical developments and prospects. Energy 2009, 34, 981-991. Available online: https:/ / www.sciencedirect.com/science/article/pii/S0360544208002855 (accessed on 20 January 2020). [CrossRef]

3. Engeda, A.; Strate, P.; Rautenberg, M. Auswahl von Kreiselpumpen als Turbinen. Pumpentagung Karlsruhe 1988, 88, 12-19.

4. Sharma, R.L. Pumps as turbines for small hydro. Indian J. Power River Val. Dev. 1999, 49, 44-48.

5. Isbăşoiu, E.C.; Bucur, D.M.; Ghergu, C.M.; Dunca, G. Using standard pumps as turbines. In Proceedings of the CEEX 2007 Conference at Brasov; 2007; pp. 1-5. Available online: https://www.researchgate.net/publication/281645536_USING_STANDARD_ PUMPS_AS_TURBINES (accessed on 1 January 2007).

6. Van Antwerpen, H.J.; Greyvenstein, G.P. Use of turbines for simultaneous pressure regulation and recovery in secondary cooling water systems in deep mines. Energy Convers. Manag. 2005, 46, 563-575. [CrossRef]

7. Bohl, W. Strömungsmaschinen 1-Aufbau und Wirkungsweise. Aufl. Würzbg. 1994, 77, 131-132. Available online: https: //www.researchgate.net/publication/37406102_Stromungsmaschinen_1_Aufbau_und_Wirkungsweise (accessed on 5 February 2021).

8. Avellan, F. Introduction to cavitation in hydraulic machinery. In Proceedings of the International Conference on Hydraulic Machinery and Hydrodynamics, Timisoara, Romania, 21-22 October 2004; pp. 11-22.

9. Escaler, X.; Egusquiza, E.; Farhat, M.; Avellan, F.; Coussirat, M. Detectionof cavitation in hydraulic turbines. Mech. Syst. Signal. Process. 2006, 20, 983-1007. [CrossRef]

10. Gantar, M. Propeller pump running as turbines. Conference on Hydraulic Machinery. 1988, pp. 237-248. Available online: https:/ / www.researchgate.net/publication/304998834_Propeller_pump_running_as_turbines (accessed on 1 January 1988).

11. Barrio, R.; Fernandez, J.; Parrondo, J.; Blanco, E. Performance prediction for a centrifugal pump working in direct and reverse mode using computational fluid dynamics. Renew. Energies Power Qual. J. 2010, 1, 1429-1433. [CrossRef]

12. Yang, S.S.; Liu, H.L.; Kong, F.Y.; Xia, B.; Tan, L.W. Effects of the Radial Gap Between Impeller Tips and Volute Tongue Influencing the Performance and Pressure Pulsations of Pump as Turbine. J. Fluids Eng. 2014, 136. [CrossRef]

13. Su, X.; Huang, S.; Zhang, X.; Yang, S. Numerical Research on Unsteady Flow Rate Characteristics of Pump as Turbine. Renew. Energy 2016, 94, 488-495. [CrossRef]

14. Kaupert, K.A.; Staubli, T. The unsteady pressure field in a high specific speed centrifugal pump impeller-part I: Influence of the volute. J. Fluids Eng. Trans. ASME 1999, 3, 621-626. [CrossRef]

15. Spence, R.; Purdom, T. Numerical prediction of transient loadings on multistage pump impellers. In Advances of CFD in Fluid Machinery Design; IMechE: London, UK, 2003.

16. Stanmore, L.K. Field problems relating to high-energy centrifugal pumps operating at part-load. IMechE Conference C 1988, 88 , 343.

17. Zuo, Z.; Liu, S.; Sun, Y. Pressure fluctuations in the vaneless space of High-head pump-turbines-A review. Renew. Sustain. Energy Rev. 2015, 41, 965-974. [CrossRef]

18. Barrio, R.; Fernandez, J.; Blanco, E.; Parrondo, J. Estimation of radial load in centrifugal pumps using computational fluid dy namics. Eur. J. Mech. B Fluids 2011, 30, 316-324. [CrossRef]

19. Gülich, J.F. Centrifugal Pumps; Springer: Berlin/Heidelberg, Germany, 2008.

20. Jiang, Y.Y.; Yoshimura, S.; Imai, R.; Katsura, H.; Yoshida, T.; Kato, C. Quantitative evaluation of flow-induced structural vibra tion and noise in turbomachinery by full-scale weakly coupled simulation. J. Fluids Struct. 2007, 23, 531-544. [CrossRef]

21. Su, X.; Huang, S.; Li, Y.; Zhu, Z.; Li, Z. Numerical and Experimental Research on Multi-Stage Pump as Turbine System. Int. J. Green Energy 2017, 14, 996-1004. [CrossRef]

22. Gülich, J.F. Turbine operation, general characteristics. In Centrifugal Pumps; Gülich, J.F., Ed.; Springer: Berlin/Heidelberg, Germany, 2010; pp. 715-740. [CrossRef] 